\title{
P.Re.Val.E.: outcome research program for the evaluation of health care quality in Lazio, Italy
}

\author{
Danilo Fusco ${ }^{1 *}$, Anna P Barone ${ }^{1}$, Chiara Sorge ${ }^{1}$, Mariangela D'Ovidio ${ }^{1}$, Massimo Stafoggia ${ }^{1}$, Adele Lallo ${ }^{1}$, \\ Marina Davoli' and Carlo A Perucci
}

\begin{abstract}
Background: P.Re.Val.E. is the most comprehensive comparative evaluation program of healthcare outcomes in Lazio, an Italian region, and the first Italian study to make health provider performance data available to the public. The aim of this study is to describe the P.Re.Val.E. and the impact of releasing performance data to the public.

Methods: P.Re.Val.E. included 54 outcome/process indicators encompassing many different clinical areas. Crude and adjusted rates were estimated for the 2006-2009 period. Multivariate regression models and direct standardization procedures were used to control for potential confounding due to individual characteristics. Variable life-adjusted display charts were developed, and 2008-2009 results were compared with those from 20062007.

Results: Results of 54 outcome indicators were published online at http://www.epidemiologia.lazio.it/prevale10/ index.php.

Public disclosure of the indicators' results caused mixed reactions but finally promoted discussion and refinement of some indicators.

Based on the P.Re.Val.E. experience, the Italian National Agency for Regional Health Services has launched a National Outcome Program aimed at systematically comparing outcomes in hospitals and local health units in Italy.

Conclusions: P.Re.Val.E. highlighted aspects of patient care that merit further investigation and monitoring to improve healthcare services and equity.
\end{abstract}

\section{Background}

Over the last two decades, there has been increasing interest in the development and implementation of outcome and process indicators. Such indicators encourage accountability and improvements in the quality of health care services; they also guide accreditation and health care planning interventions [1-6]. Public and private organizations, as well as research projects, have used different indicators for comparative evaluation of the performance of healthcare providers and professionals. Some have released their results to the public in the form of web-based reports that compare hospital quality [7-13].

In Italy, national and regional outcome research programs have been conducted, but there has been no systematic comparison of outcomes at the national level.

\footnotetext{
* Correspondence: fusco@asplazio.it

'Department of Epidemiology, Regional Health Service-Lazio Region, via

Santa Costanza 53, Rome, 00198, Italy

Full list of author information is available at the end of the article
}

The Mattoni-Outcome Project, funded by the Italian Ministry of Health [13], and the subsequent Progr.Es.Si. Project, have been the main national experiences in this field. The Mattoni-Outcome Project methodologies were the starting point for the Regional Outcome Evaluation Program, called P.Re.Val.E. [14,15], which was conducted in the Lazio region of Italy $(5,493,308$ residents [16]). P. Re.Val.E. is the most comprehensive comparative evaluation of regional healthcare outcomes and the only Italian study to publicly disclose performance data.

The objectives of P.Re.Val.E. were to define and evaluate outcome/process indicators in order to:

- compare the outcomes of health care provided by different hospitals or in different geographical areas for purposes such as accreditation, remuneration, and enhancing citizen empowerment;
C Biomed Central 
- compare population subgroups (e.g. socioeconomic subgroups), especially for evaluating and promoting equitable service provision;

- identify the minimum volume of activity associated with the best treatment outcomes;

- promote internal and external auditing;

- identify critical areas in which to implement programs that improve health care quality;

- monitor trends in health care quality over time.

In order to highlight differences in the performance of local commissioning authorities, P.Re.Val.E evaluated outcomes according to patient residence. Importantly, direct standardization methods [17-20] rather than indirect standardization methods $[5,7,10,20]$ were used for the comparative evaluation of outcomes. The aim of this report is to describe the P.Re.Val.E. program, including information sources, statistical methodologies, results for 2006-2009 (published online at http://www.epidemiologia.lazio.it/ vislazio/vis_index.php, and the updated Italian version at http://www.epidemiologia.lazio.it/prevale10/index.php), and the impact of releasing performance data to the public.

\section{Methods}

\section{Study design and data sources}

We defined 54 performance indicators in different clinical areas that included treatment for cardiac, cerebrovascular, orthopedic, obstetric, respiratory, and digestive disorders [14]. Some were health outcome indicators, such as 30day mortality after an episode of myocardial infarction or 30-day complications after cholecystectomy; others were process indicators for which an association with improved health outcomes has been already proven, such as intervention within 48 hours of hospital admission for hip fracture in the elderly. Finally, hospitalization rates for pathologies generally treated out of the hospital, such as diabetes, asthma, and influenza, were considered an indication of failure in primary care [21].

Most indicators were selected based on their previous use in international and national studies [7-19,21-24], while other indicators were developed in order to describe particular components of care or clinical pathways. A rationale and a detailed operative protocol were elaborated for each indicator according to a standard outline [14]. The indicators were defined using information collected from regional health information systems covering the whole Lazio population: the Hospital Information System (HIS), the Emergency Information System (EIS), the Mortality Information System (MIS), the Report AdmissionDischarge for Rehabilitation (RADR), and the Hospital Deliveries Information System (HDIS). For detailed information about each, please see http://www.epidemiologia. lazio.it/vislazio_en/fonti.php.
The HIS database was the primary source for case selection and outcomes/comorbidities data. We also used information from the EIS database to better identify comorbidities and to estimate the time to death or time to surgery after arrival at the hospital (i.e. admission to the Emergency Department or to a hospital ward). Deaths during the study period were identified using the HIS, the EIS, and the MIS. The RADR database was used to identify admission to a rehabilitation center following hospital admission for stroke. Finally, we used the HDIS database for more accurate identification of new births, primary cesarean deliveries, and risk factors for cesarean section which are not included in the HIS.

HIS records were linked with EIS, MIS, RADR, and HDIS records using deterministic record-linkage. To ensure maximum coverage of the population while avoiding double counting, the linkage method uses a unique patient identifier deriving from information on persons' names, date and place of birth and gender, according to Italian privacy legislation.

\section{Study population}

P.Re.Val.E. analyzed hospital discharges in the Lazio region in the 2006-2009 period [14]. Most data were expressed as ratios in which the numerator represents the number of treatments/interventions provided or the number of patients with a given outcome (i.e., short-term mortality, hospitalization for specific conditions, etc.) and the denominator represents the group of patients at risk. In other cases, the indicators were defined as survival/waiting time (e.g., the wait for surgery after hip fracture).

The analyses were performed, two years over two years, by area of residence regardless of the hospital at which the patient was treated and by hospital.

\section{Definition and attribution of outcome}

The outcome measures were as follows: 30-day mortality, short-term re-hospitalization, hospitalization for specific conditions, surgical procedures, short-term complications of specific interventions, and waiting times. The outcomes under study were attributed to the first emergency department at which the patient was treated (first access) or to the first admission hospital and to the area of residence.

\section{Coexisting medical conditions}

Chronic comorbidities and/or severity characteristics that were potentially associated with the outcomes under study were chosen using information in the literature [7-9,17,18,21-23,25-30] and in the Mattoni-Outcome project [13]. The potential risk factors were identified on the basis of ICD-9-CM codes registered either during hospitalization for the condition under study (index hospitalization) or in previous hospital or emergency department admissions during the previous two years. Acute 
events occurring during the index hospitalization, which could be complications of care/treatments (i.e. on the causal pathway between exposure and outcome), were not included.

\section{Statistical analysis}

Statistical analyses were performed by first admission or access hospital as well as by area of residence. Since patient characteristics, such as age, sex, severity of disease, and/or chronic comorbidities, could be heterogeneously distributed across the hospitals/areas of residence, risk-adjustment methods were applied [31]. The risk adjustment procedure involved construction of a severity measure ("a priori" risk) that was specific for the study population and the use of this measure to obtain "adjusted" outcome measures for comparison between hospitals/areas. The severity measure was calculated by analyzing the multivariate relationship between possible outcome predictors and the outcome considered by application of multivariate regression models (predictive models) including: 1) a priori risk factors (age, sex, and/or severity of the condition being investigated); and 2) factors selected by a bootstrap stepwise procedure. Stepwise analysis was performed with 500 replicated samples of the original data and significance thresholds of 0.10 and 0.05 for entry and removal, respectively.

Only risk factors (pre-existing chronic conditions, etc.) selected in at least $50 \%$ of the runs were included in the final models

We used logistic regression models for dichotomous outcome variables and survival models for outcomes expressed in terms of survival times. In order to estimate adjusted group-specific (hospital/area of residence) log odds of outcome, logistic regression models with no intercept and centred covariates were applied for each outcome. Adjusted risks were obtained for each group by back-transforming parameter estimates with the following formulas:

$$
\text { Adj risk }=[\exp (\text { estimate }) /(1+\exp (\text { estimate }))]^{*} \mathrm{k}
$$

where $\mathrm{k}$ is a correction coefficient introduced to take into account the nonlinear nature of the logistic model. $\mathrm{K}$ is calculated as follows:

$$
k=\frac{\text { actual_number_of_events }}{\sum_{j=1}^{m} p_{j} * n_{j}}
$$

where $p_{j}$ are the adjusted risks, $n_{j}$ is the group size, and $m$ is the number of groups.

This approach allowed comparison of the outcome for a given facility or area of residence with that of the whole study population and with each of the other facilities/ areas $[18,32,33]$. In order to assess for cluster effects, we used the cluster sandwich ("robust") variance-covariance estimators, relaxing the usual requirement that the observations are independent. According to this methodology, the observations are independent across groups but not necessarily within groups.

The adjusted RR estimated for each hospital/area of residence, the adjusted risk or median waiting time, and the corresponding p-value were reported on-line in tabular and graphical forms.

For each indicator, trend analyses and comparisons of the 2008-2009 data versus the 2006-2007 data were developed by hospital and area of residence.

Variable Life-Adjusted Display (VLAD) charts [34,35] were constructed to identify the principal increases/ decreases and trend reversals in the cumulative sums of the differences between the number of events observed (deaths, rehospitalizations, reoperations, complications, etc.) and the number expected based on the predictive model. Two tests of statistical significance were performed, the first to determine whether during the study period, the number of events observed in one month (from the second day of the previous month to the first day of the following month) was significantly different from the number of expected events and the second to determine whether the number of observed events between 2 trend-reversal points was significantly different from the number of expected events. Both significance tests were performed using the ratio of observed to expected events assuming a Poisson distribution.

Finally, since higher activity volumes of the hospitals are often associated with better outcomes, we also investigated those relationships (displayed as scatter plots).

The level of statistical significance was set at 5\% (p < 0.05 ), and all analyses were performed using SAS Version 8.2 [36].

\section{Preliminary disclosure of performance data to clinicians and providers}

Before public release of data, we shared the P.Re.Val.E methods and results with different groups of clinicians and providers, to promote discussion and encourage contributions and critical assessments.

\section{Results}

We calculated 54 indicators, 9 of which were prevention quality indicators, that covered almost $40 \%$ of all hospital admissions in the Lazio Region during the 2008-2009 period. The results obtained for all indicators, available online at http://www.epidemiologia.lazio.it/prevale10/ index.php, showed a great heterogeneity of the healthcare quality in the Lazio region.

Public disclosure of the indicators' results caused mixed reactions but finally promoted discussion and refinement of some indicators, e.g., for 30-day mortality 
after aortic aneurysm. These meetings led to new estimates for some indicators and stimulated audit activities among clinicians and healthcare organizations.

In 2008, Agency for Public Health of Lazio designed a clinical pathway for elderly patients with hip fracture. The clinical pathway was tested in five selected hospitals before the implementation in all Lazio hospitals.

In 2009, a regional health service regulation went into effect that required Lazio hospitals to adopt the clinical pathway for elderly patients with hip fracture and that introduced a compensation system for hospitals based on quality of healthcare (as in a pay-for-performance model). The DRG reimbursement rate for Lazio providers was linked to hospital performance. In fact, from 2009 on, the full DRG rate has only been paid for patients who underwent surgical treatment within 48 hours after admission, while rates for interventions performed after 48 hours were reduced proportionally based on the time to surgery.

Based on the P.Re.Val.E. experience, the Italian National Agency for Regional Health Services has launched a National Outcome Program aimed at systematically comparing outcomes in hospitals and local health units in Italy.

As an example, results pertaining the 30-day mortality rate after hospital admission for acute myocardial infarction (AMI) in Lazio region were shown [for the operative protocol see: additional File 1, Appendix: operative protocol].

There were 16, 682 AMI episodes in 2008-2009 with a mean mortality rate of $11.1 \%$ (men: $8.9 \%$; women: $15.2 \%$ ). The probability of death was 2 times higher when chronic diseases (liver, pancreas, intestine) in the index admission, cancer and other cardiac operations were present (Table 1).
The adjusted mortality rates ranged from $6.7 \%$ to $19.2 \%$ in different hospitals, and from $8.8 \%$ to $13.7 \%$ for different areas of residence (Tables 2 and 3). In the previous 2-year period there were 17436 AMI episodes, the mean mortality rate was $12.2 \%$, with high variability among the different facilities and areas. In general, the adjusted mortality rates showed a small decrease over time for most facilities and areas (data not shown). Although the VLAD charts were developed for each facility and area, the results from two large hospitals that showed very different time trends for 30-day mortality after AMI admission were reported only. In 2008-2009, Presidio Ospedaliero Nord, Latina, showed a greater number of observed deaths after AMI admission than expected, with a little decrease in November 2009 (Figure 1), whereas San Filippo Neri, Rome, generally had fewer observed events than expected ones (Figure 2).

\section{Discussion and Conclusions}

Comparative evaluation of hospital performance is a useful tool for improving health care quality $[1,4]$. The U.S. experience has shown that public disclosure of comparative evaluation results should be managed as one component of an integrated quality improvement strategy, and that the public release of performance data is most effective at the level of the provider organization [3,4,37]. Regular feedback seems to increase the accountability of providers, which are sensitive to public image and potential legal risks; it can also spur quality improvement activities in health care organizations, especially when underperforming areas are identified [38]. However, providers that are identified as poor performers are more likely to question the validity of the data, particularly when the results are first released [39].

Table 1 Acute myocardial infarction: mortality within $\mathbf{3 0}$ days of hospital admission, predictive model

\begin{tabular}{|c|c|c|c|c|}
\hline Risk Factors & $\mathbf{N}$ & Crude OR & Adjusted OR & $\mathrm{p}$ \\
\hline Age (years) & - & 1.08 & 1.08 & 0.000 \\
\hline Gender (Females vs Males) & 5767 & 1.84 & 1.05 & 0.419 \\
\hline Cancer & 810 & 2.52 & 2.05 & 0.000 \\
\hline Hypertention & 3072 & 1.52 & 0.85 & 0.024 \\
\hline Previous myocardial infarction & 2481 & 0.96 & 0.73 & 0.000 \\
\hline Cardiomyopathy (index admission) & 259 & 0.82 & 0.63 & 0.040 \\
\hline Cardiomyopathy & 218 & 1.88 & 1.14 & 0.505 \\
\hline Heart failure & 1117 & 2.77 & 1.62 & 0.000 \\
\hline Other heart conditions (index admission) & 367 & 1.06 & 0.60 & 0.006 \\
\hline Other heart conditions & 228 & 1.83 & 1.08 & 0.688 \\
\hline Cerebrovascular disease & 1122 & 2.43 & 1.47 & 0.000 \\
\hline Vascular disease & 679 & 2.23 & 1.57 & 0.000 \\
\hline Chronic renal disease & 876 & 2.82 & 1.66 & 0.000 \\
\hline Other chronic disease (liver, pancreas, intestine) (index admission) & 105 & 2.52 & 2.33 & 0.001 \\
\hline Other chronic disease (liver, pancreas, intestine) & 209 & 1.98 & 1.35 & 0.135 \\
\hline Previous coronary angioplasty & 1417 & 0.57 & 0.65 & 0.000 \\
\hline Other cardiac interventions & 127 & 1.69 & 2.06 & 0.006 \\
\hline
\end{tabular}


Table 2 Acute myocardial infarction: mortality within 30 days of hospital admission, by health care facility

\begin{tabular}{|c|c|c|c|c|c|c|}
\hline Hospital & Location & $\mathrm{N}$ & Crude rate $\times 100$ & Adjusted rate $\times 100$ & Adjusted RR & $p$ \\
\hline OSP. S. CAMILLO DE LELLIS & RIETI & 509 & 12.57 & 12.23 & 1.10 & 0.461 \\
\hline OSP. S. SPIRITO & ROME & 574 & 10.28 & 8.43 & 0.76 & 0.049 \\
\hline OSP. ANZIO-NETTUNO & ANZIO & 351 & 9.69 & 9.11 & 0.82 & 0.269 \\
\hline OSP. ALBANO-GENZANO & ALBANO & 361 & 13.02 & 12.75 & 1.15 & 0.366 \\
\hline OSP.S. PAOLO & CIVITAVECCHIA & 298 & 14.77 & 13.86 & 1.25 & 0.162 \\
\hline OSP. PARODI DELFINO & COLLEFERRO & 320 & 8.75 & 8.23 & 0.74 & 0.129 \\
\hline OSP. S. SEBASTIANO & FRASCATI & 250 & 12.80 & 11.99 & 1.08 & 0.675 \\
\hline OSP. S. GIOVANNI EVANG & TIVOLI & 200 & 19.50 & 19.17 & 1.73 & 0.001 \\
\hline OSP. GRASSI & ROME & 648 & 9.72 & 9.17 & 0.83 & 0.152 \\
\hline OSP. S. EUGENIO & ROME & 485 & 13.81 & 12.25 & 1.10 & 0.454 \\
\hline OSP. S.PIETRO F.B.F. & ROME & 232 & 12.93 & 14.02 & 1.26 & 0.216 \\
\hline OSP. VANNINI & ROME & 706 & 10.62 & 10.89 & 0.98 & 0.874 \\
\hline CC S. ANNA & POMEZIA & 179 & 12.29 & 17.45 & 1.57 & 0.034 \\
\hline CC NUOVA ITOR & ROME & 258 & 14.73 & 10.60 & 0.96 & 0.792 \\
\hline CC CITTA' ROMA & ROME & 203 & 8.37 & 6.72 & 0.61 & 0.046 \\
\hline CC AURELIA HOSPITAL & ROME & 396 & 10.35 & 10.59 & 0.95 & 0.775 \\
\hline PRES. OSP. NORD & LATINA & 690 & 11.30 & 13.49 & 1.22 & 0.096 \\
\hline PRES. OSP. SUD & FORMIA & 500 & 11.80 & 13.16 & 1.19 & 0.204 \\
\hline CC CITTA' DI APRILIA & APRILIA & 245 & 13.47 & 13.48 & 1.22 & 0.286 \\
\hline OSP. UMBERTO I & FROSINONE & 556 & 9.17 & 10.07 & 0.91 & 0.502 \\
\hline OSP. CIVILE & ANAGNI & 152 & 9.87 & 10.98 & 0.99 & 0.968 \\
\hline OSP. S.S.TRINITA' & SORA & 220 & 10.91 & 11.44 & 1.03 & 0.885 \\
\hline OSP. G. DE BOSIS & CASSINO & 222 & 9.46 & 8.85 & 0.80 & 0.323 \\
\hline OSP. S. PERTINI & ROME & 763 & 11.40 & 11.99 & 1.08 & 0.491 \\
\hline OSP. BELCOLLE & VITERBO & 602 & 10.96 & 12.40 & 1.12 & 0.386 \\
\hline A.O. S. CAMILLO-FORLANINI & ROME & 1021 & 12.83 & 13.00 & 1.17 & 0.088 \\
\hline A.O. S. GIOVANNI & ROME & 679 & 7.81 & 7.52 & 0.68 & 0.007 \\
\hline A.O. S.FILIPPO NERI & ROME & 770 & 10.91 & 11.58 & 1.04 & 0.708 \\
\hline POLICLINICO A. GEMELLI & ROME & 695 & 8.06 & 7.73 & 0.70 & 0.011 \\
\hline POLICLINICO UMBERTO I & ROME & 557 & 10.23 & 11.88 & 1.07 & 0.619 \\
\hline A.O. S. ANDREA & ROME & 615 & 4.88 & 6.16 & 0.55 & 0.001 \\
\hline A.O. POL. TOR VERGATA & ROME & 505 & 5.94 & 9.67 & 0.87 & 0.451 \\
\hline
\end{tabular}

RR: Relative Risk

In Italy, initiatives aimed at assessing the outcomes of hospital care have been undertaken at the national and regional levels only in the last decade $[13,17,40,41]$. Based on these experiences, we developed the Regional Outcome Evaluation Program, called P.Re.Val.E. [14]. The high numbers of patients investigated, the accuracy in the selection of the cohorts and the study outcomes, the consolidated statistical strategy, and the replication of similar findings for different clinical conditions are important elements of internal and external validity. For 2006-2009, results were obtained using direct risk adjustment for comparative evaluation of outcomes for hospitals and areas of residence. Hospital league tables obtained by indirect standardization procedures should not be used for hospital-to-hospital comparisons [20]. This technique can lead to biased conclusions unless the distribution of risk factors or their effects do not vary between the hospitals being compared.

After receiving comparative reports based on standardized performance measures, hospitals that began as low-level performers tended to improve faster than those that started at higher levels of performance [42].

Since studies have shown little correlation between measured quality of care and Standardized Mortality Ratios (SMRs) $[43,44]$, we used different outcome and/or process measures for each studied condition to better identify the hospitals/geographic areas that needed health care quality improvement. This study used data from several health care information systems, and most of the indicators were based on the concept of first hospital access, corresponding to patient admission to an acute inpatient facility or to emergency department access. The indicators for which 
Table 3 Acute myocardial infarction: mortality within $\mathbf{3 0}$ days of hospital admission, by area of residence

\begin{tabular}{|c|c|c|c|c|c|}
\hline Area & $\mathrm{N}$ & Crude rate $\times 100$ & Adjusted rate $\times 100$ & Adjusted RR & $p$ \\
\hline Rome District I & 385 & 10.39 & 9.31 & 0.84 & 0.297 \\
\hline Rome District II & 312 & 10.90 & 8.80 & 0.79 & 0.202 \\
\hline Rome District III & 129 & 15.50 & 12.39 & 1.12 & 0.641 \\
\hline Rome District IV & 567 & 9.70 & 9.04 & 0.82 & 0.152 \\
\hline Rome District V & 709 & 10.86 & 11.13 & 1.00 & 0.982 \\
\hline Rome District VI & 515 & 11.65 & 11.06 & 1.00 & 0.981 \\
\hline Rome District VII & 298 & 9.40 & 9.86 & 0.89 & 0.546 \\
\hline Rome District VIII & 565 & 9.03 & 10.96 & 0.99 & 0.932 \\
\hline Rome District IX & 351 & 12.25 & 10.06 & 0.91 & 0.548 \\
\hline Rome District X & 454 & 9.69 & 10.44 & 0.94 & 0.696 \\
\hline Rome District XI & 415 & 14.70 & 12.49 & 1.13 & 0.387 \\
\hline Rome District XII & 427 & 11.94 & 11.26 & 1.01 & 0.922 \\
\hline Rome District XIII & 700 & 11.43 & 10.92 & 0.98 & 0.891 \\
\hline Fiumicino & 221 & 9.50 & 9.90 & 0.89 & 0.620 \\
\hline Rome District XV & 445 & 11.46 & 10.31 & 0.93 & 0.623 \\
\hline Rome District XVI & 424 & 12.97 & 11.52 & 1.04 & 0.794 \\
\hline Rome District XVII & 268 & 13.43 & 10.19 & 0.92 & 0.636 \\
\hline Rome District XVIII & 393 & 12.72 & 11.46 & 1.03 & 0.827 \\
\hline Rome District XIX & 594 & 11.62 & 10.05 & 0.91 & 0.444 \\
\hline Rome District XX & 414 & 11.84 & 12.84 & 1.16 & 0.329 \\
\hline ASL RM/F & 894 & 10.07 & 10.04 & 0.90 & 0.368 \\
\hline ASL RM/G & 1278 & 10.95 & 11.78 & 1.06 & 0.500 \\
\hline ASL RM/H & 1693 & 10.16 & 10.92 & 0.98 & 0.846 \\
\hline Viterbo & 182 & 9.34 & 8.77 & 0.79 & 0.347 \\
\hline Viterbo Province & 741 & 12.42 & 13.08 & 1.18 & 0.132 \\
\hline Rieti & 181 & 9.39 & 9.37 & 0.84 & 0.504 \\
\hline Rieti Province & 329 & 13.37 & 13.16 & 1.19 & 0.281 \\
\hline Latina & 307 & 11.73 & 12.45 & 1.12 & 0.511 \\
\hline Latina Province & 1223 & 11.37 & 12.73 & 1.15 & 0.124 \\
\hline Frosinone & 180 & 11.67 & 13.71 & 1.24 & 0.345 \\
\hline Frosinone Province & 1088 & 9.93 & 10.62 & 0.96 & 0.662 \\
\hline
\end{tabular}

RR: Relative Risk

time to death or to surgery was calculated from first hospital access provide a measure of the appropriateness and efficacy of the health care process that begins when a patient arrives to a given facility. Use of the MIS and EIS databases, in addition to the HIS database, allowed more accurate identification of 30-day mortality.

To monitor the time trends of the different outcomes, we used VLAD charts, a type of quality control chart that is a good tool for measuring the variability of an event adjusting for patient risk $[34,35,45,46]$. VLAD charts provide an easy-to-understand and up-to-date view that allows early detection of runs of good or bad outcomes and thus can prompt timely intervention for critical situations. The VLAD charts also highlight small variations over time for observed events compared to expected events; this information is often obscured by the corresponding synthetic indicator.
The P.Re.Val.E. results for 2008-2009 [14] provided an overview of the hospital care heterogeneity in the Lazio region. The results do not constitute a "league table" of performance, but instead reveal numerous instances of high-quality care as well as problem areas that merit further analysis and internal and external auditing as part of an increasingly well-developed program of clinical governance.

P.Re.Val.E. is an outcome research program conceived mainly as a tool for promoting discussion among healthcare managers and professionals in the Lazio region. Given the complexities of accurately comparing provider outcomes, we published the methods used for developing the program in detail, using others' suggestions for the public reporting of comparative health outcome evaluations [47] so that the face validity of the results could be evaluated. We also used various tools to present the 

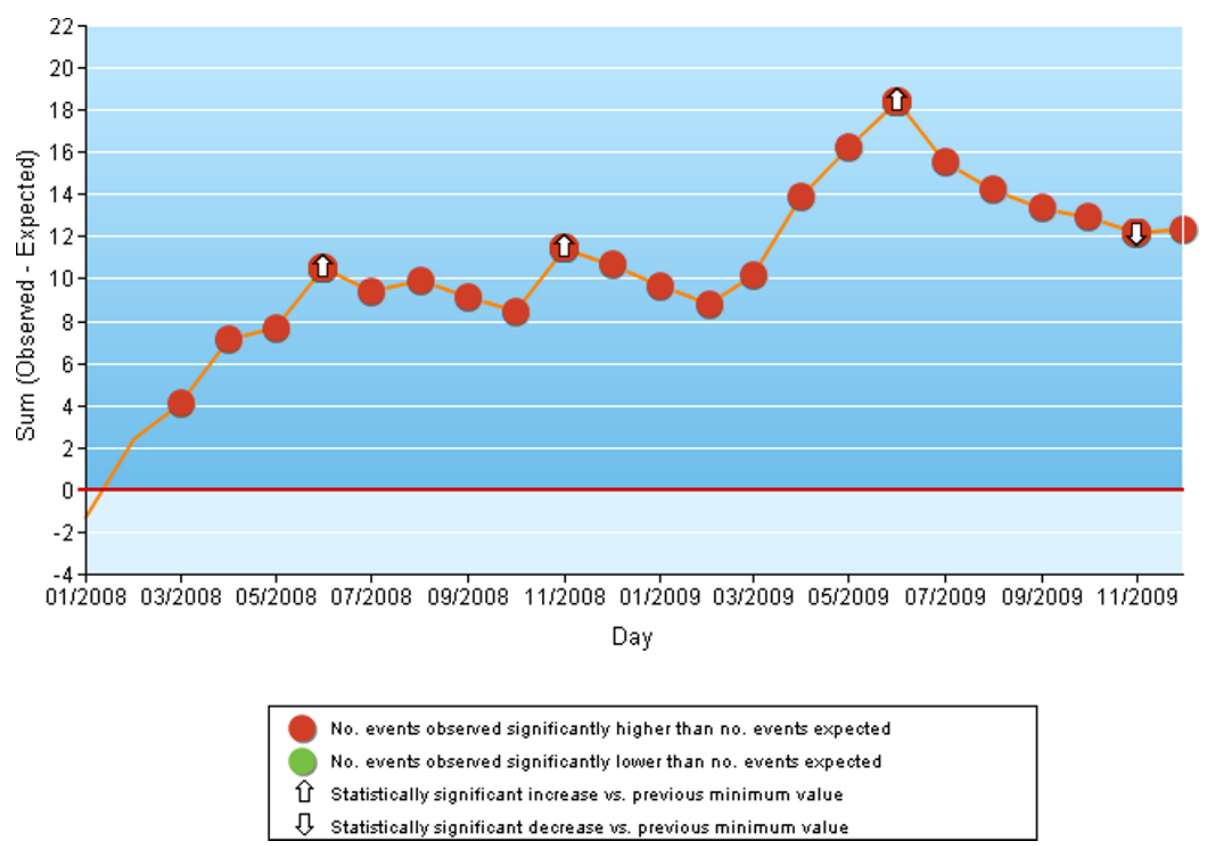

Figure 1 VLAD chart. Acute myocardial infarction: mortality within 30 days of hospital admission. Hospital Presidio Ospedaliero Nord, Latina.

results in order to make the results accessible; in particular, we used bar graphs to clearly display adjusted estimates, as well as tables that included the number of admissions, the crude and adjusted estimates, and the statistical significance of the results.

Public disclosure of the 2006-2009 results to clinicians, health care managers, and policy makers was aimed at creating an incentive to improve results. In fact, studies describing the effect of public reporting on consumers' choices, effectiveness, patient safety and patient-centeredness have shown that the public release of performance data mainly stimulates change at hospital level [48]. There have been some negative reactions, but in most cases, the results have stimulated increased

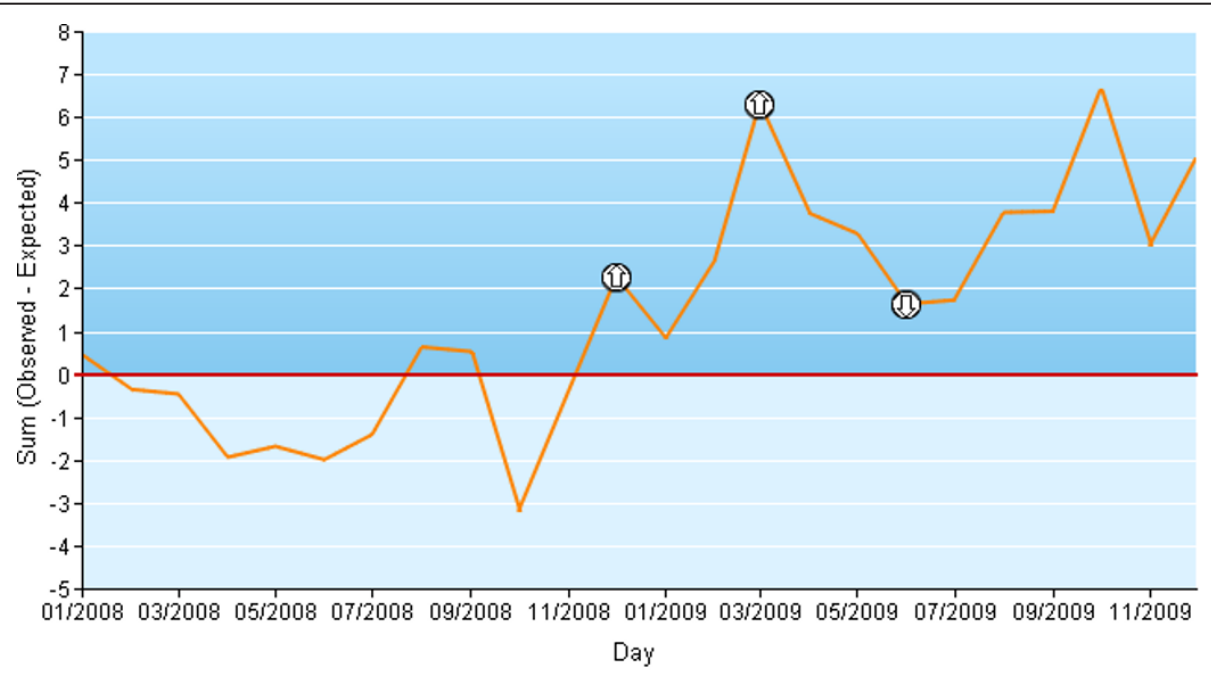

No. events obsenved significantly higher than no. events expected
No. events obsened significantly lower than no. events expected
I Statistically significant increase vs. previous minimum value
I Statistically significant decrease vs. previous minimum value

Figure 2 VLAD chart. Acute myocardial infarction: mortality within 30 days of hospital admission. Hospital S. Filippo Neri, Rome. 
review among health care organizations and professionals. Clinicians and program developers have met several times to discuss the methodology as well as negative findings, such as poor performance or poor coding accuracy. Physicians have made suggestions about more accurate selection criteria for some indicators. As a consequence of the extremely low proportion of interventions for hip fracture in the elderly within 48 hours in most facilities, the regional authority decided that hospitals with performance results below a given standard would be penalized economically by a reduction in fees corresponding to specific Diagnosis Related Groups (DRGs) [49].

P.Re.Val.E. is a program in progress, and it will be updated and further developed by the definition and calculation of additional indicators, e.g., those aimed at evaluating health care quality for oncology patients, and by the use of regional drug dispensing registries to more accurately identify patient comorbidities. The impact of health care performance information disclosure to the general public should be evaluated. Evidence suggests that this information has only a limited impact on consumer decision-making [39] since people have limited access to data on health care providers [50]; however, studies suggest that people are interested in comparative information [51,52].

These analyses have explicit limitations, especially with regard to the marked variability in the coding accuracy of current health care information systems. This issue is critical for ensuring accurate risk adjustment, and, correspondingly, reliable comparative quality ratings [53]. In the past, administrative databases have too frequently been used exclusively as tools to claim financial reimbursement for services provided without concern for their roles as epidemiologic sources and as essential instruments for clinical governance. There are some important advantages to routinely collecting administrative data: it is inexpensive to do this, and the data provide information about large populations, do not depend on voluntary participation by individual clinicians and providers, and can be used to predict risk of death with discrimination comparable with that obtained from clinical databases [54]. However, the use of routinely collected administrative data in comparative outcome evaluations has been criticized for the following reasons: there is an absence of clinical information needed to adequately adjust for patients' conditions [55,56]; there is an inability to distinguish between a disease present at admission (a comorbidity, i.e. a true patient risk factor) and one that occurred during the hospital stay (i.e. a complication) $[56,57]$ and some chronic comorbidities, such as hypertension and diabetes, are known to be currently underreported at admission, mainly in more severely affected patients $[58,59]$. The first problem could be overcome in the P.Re.Val.E. update for 3 conditions, namely AMI, aortocoronary bypass, and hip fracture, since some clinical information (e.g., systolic blood pressure, ejection fraction, creatinine) have been recently added to the HIS [60]. Moreover, in these 3 conditions, intrinsic illnesses at the time of patients' admissions can be distinguished from complications since "present on admission" (POA) flags have been added to discharge diagnoses [61]. The problem of under-recording is also partially solvable by using prior patient hospitalization records to identify comorbidities independent of patient severity at the current admission [61] as well as emergency department visits to collect additional information about patient risk factors. However, the coding accuracy may differ widely among the facilities [62], and this could lead to biased comparisons. Even though the possibility of gaming of the data in response to the performance evaluation cannot be excluded, previous studies did not find evidence of gaming [63]. Some studies have reported that changes in data accuracy may partially explain quality improvement [64]. However, we did not find relevant changes in recording of co-morbidities in our study population over the years (data not shown). In agreement with previous reports, the prevalence of certain co-morbidities and risk factors was relatively low in our study population, indicating underreporting of co-morbidities and detailed clinical information in the administrative database [65]. However, underreporting was non-differential in the years included in our analysis. Moreover, a previous Italian study [65] assessing clinical performance in cardiac surgery demonstrated that the use of an administrative database provided similar league tables as a more complex specialized database.

Finally, since health care services can only be evaluated by empirical measurements, inevitably there will be errors (systematic and random). This represents a clear limitation of our analysis as well as others of this type. We agree with Shahian et al. that hospital mortality estimates could vary, sometimes widely, based on the different case-selection criteria and statistical methods, leading to divergent inferences about relative hospital performance. Despite these concerns, some findings could be useful to potential users or to facilities [66]. P.Re.Val.E. openly declares the data sources and methods, allowing external review of biases and distortions implicit to the evaluation process. The next P.Re.Val.E. analysis, expected in November 2011, will include improvements in methods and procedures; of course, we cannot say that other biases will not be introduced, simply that they will be different. It is our conviction, however, that P.Re.Val.E. is an important operative tool that should be used to promote clinical and organizational monitoring of health care providers, to support political decision-making processes, and to stimulate a sense of healthy, productive competition aimed at improving 
healthcare efficacy and equity. We hope that this program will encourage a value often neglected within the Italian NHS: accountability.

\section{Additional material}

Additional file 1: Appendix: operative protocol. 30-Day Mortality Rate after hospital admission for Acute Myocardial Infarction (AMI).

\section{Acknowledgements}

We would like to thank Federica Asta, Paola Colais, Mirko Di Martino, and Martina Ventura for their support.

\section{Author details}

${ }^{1}$ Department of Epidemiology, Regional Health Service-Lazio Region, via Santa Costanza 53, Rome, 00198, Italy. ${ }^{2}$ National Agency of Regional Health Services, via Puglie 23, Rome, 00187, Italy.

\section{Authors' contributions}

DF conceived the idea, participated in the design, analysis, interpretation of data and have been involved in drafting the manuscript. APB participated in the design, interpretation of data and contributed to the manuscript preparation.

CS conducted the statistical analysis, provided technical support and contributed to the manuscript preparation. MD made substantial contributions to perform the statistical analysis. MS conducted the statistical analysis and provided technical support. AL conducted the statistical analysis and provided technical support. MD participated in the design and interpretation of data. CAP participated in the design, coordination and interpretation of data. All authors read and approved the final manuscript.

\section{Competing interests}

The authors declare that they have no competing interests.

Received: 12 January 2011 Accepted: 27 January 2012

Published: 27 January 2012

\section{References}

1. Relman AS: Assessment and accountability: the third revolution in medical care. N Engl J Med 1988, 319:1220-1222.

2. Marshall MN, Shekelle PG, Leatherman S, Brook RH: The public release of performance data: what do we expect to gain? a review of the evidence. JAMA 2000, 283:1866-1874.

3. Gibberd R, Hancock S, Howley P, Richards K: Using indicators to quantify the potential to improve the quality of health care. Int J Qual Health Care 2004, 16:i37-i43.

4. Berwick DM, James B, Coye MJ: Connections between quality measurement and improvement. Med Care 2003, 41:130-138.

5. Joint Commission on Accreditation of Healthcare Organizations (JCAHO): Specifications Manual for National Hospital Inpatient Quality Measures, version 4.0c. JCAHO 2011 [http://www.jointcommission.org/ performance_measurement.aspx].

6. Leatherman $\bar{S}$, Sutherland $K$ : The quest for quality in the NHS: refining the NHS reforms. London. The Nuffield Trust 2008, Available at:https://www. evidence.nhs.uk.

7. Agency for Healthcare Research and Quality (AHRQ): AHRQ quality indicators. Guide to inpatient quality indicators: quality of care in hospitals - volume, mortality, and utilization, version 3.1. Rockville (MD): Agency for Healthcare Research and Quality 2007 [http://www. qualityindicators.ahrq.gov/]

8. NHS - National Centre for Health Outcomes Development. Clinical and Health Outcomes Knowledge Base Care Quality Commission. [http:// www.nchod.nhs.uk].

9. Tu JV, Khalid L, Donovan LR, Ko DT: Canadian Cardiovascular Outcomes Research Team/Canadian Cardiovascular Society Acute Myocardial
Infarction Quality Indicator Panel. Indicators of quality of care for patients with acute myocardial infarction. CMAJ 2008, 179(9):909-915.

10. Health Grades. The Seventh Annual Health Grades Hospital Quality and Clinical Excellence Study. Lakewood, CO: Health Grades 2009 [http://www. healthgrades.com/media/DMS/pdf/

HospitalQualityClinicalExcellenceStudy2009.pdf].

11. EUPHORIC-EUropean Public Health Outcome Research and Indicators Collection project. [http://www.euphoric-project.eu].

12. Mattke S, Kelley E, Scherer P, Hurst J, Lapetra MLG, the HCQI Expert Group Members: Health Care Quality Indicators Project Initial Indicators Report. OECD Health Working Papers 2006, 22.

13. Ministry of Health, Italy. Mattoni-outcome project. [http://www.mattoni. salute.gov.it/].

14. Lazio Regional Health Service (RHS) Outcome Evaluation Program 2006 2009. , http://www.epidemiologia.lazio.it/vislazio/vis_index.php and http:// www.epidemiologia.lazio.it/prevale10/index.php.

15. Lazio Region. Resolution no. 301. Official Bulletin of the Lazio Region 2008, 25(77 supp.).

16. National Institute of Statistics (ISTAT), Italy. [http://demo.istat.it/pop2007/ index_e.html].

17. Agabiti N, Ancona C, Forastiere F, Arca M, Perucci CA: Evaluating outcomes of hospital care following coronary artery bypass surgery in Rome, Italy. Eur J Cardiothorac Surg 2003, 23(4):599-606, discussion 607-608.

18. Fantini MP, Stivanello E, Frammartino B, Barone AP, Fusco D, Dallolio L, Cacciari , Perucci CA: Risk adjustment for inter-hospital comparison of primary cesarean section rates: need, validity and parsimony. BMC Health Serv Res 2006, 6(1):100

19. Capon A, Di Lallo D, Perucci CA, Panepuccia L: Case-mix adjusted odds ratios as an alternative way to compare hospital performances. Eur $J$ Epidemiol 2005, 20(6):497-500.

20. Clayton D, Hills M: Statistical Models in Epidemiology. New York: Oxford University Press; 1993.

21. Agency for Healthcare Research and Quality (AHRQ). AHRQ quality indicators. Guide to prevention quality indicators. Rockville, MD: Agency for Healthcare Research and Quality. Version 3.12007 [http://www. qualityindicators.ahrq.gov/]

22. California Hospital Outcomes Project: Heart Attack Outcomes 1996-1998. Volume 2: Technical Guide. OSHPD 2002.

23. CCORT/CCS Acute Myocardial Infarction Canadian Quality Indicator Panel. [http://www.ccort.ca/].

24. Commission for Health Improvement. Performance indicators \& ratings for 2002/2003 Indicator listings for Acute trusts. [http://www.chi.nhs.uk/ Ratings/Trust/Indicator/indicators.asp?trustType=1].

25. Champney KP, Frederick PD, Bueno H, Parashar S, Foody J, Bairey Merz CN Canto JG, Lichtman JH, Vaccarino V: The Joint Contribution of Sex, Age and Type of Myocardial Infarction on Hospital Mortality Following Acute Myocardial Infarction. Heart 2009, 95(11):895-899.

26. New York State Department of Health. Percutaneous coronary interventions (PCI) in New York State 2004-2006. Albany, New York: New York State Department of Health; 2009 [http://www.health.state.ny.us/ statistics/diseases/cardiovascular/].

27. Ugolini C, Nobilio L: Risk adjustment for coronary artery bypass graft surgery: an administrative approach versus EuroSCORE. Int J Qual Health Care 2004, 16(2):157-164

28. Gudmundsson G, Gislason T, Lindberg E, Hallin R, Ulrik CS, Brondum E, Nieminen MM, Aine T, Bakke P, Janson C: Mortality in COPD patients discharged from hospital: the role of treatment and co-morbidity. Respir Res 2006, 7:109

29. Löfvendahl S, Eckerlund Ir, Hansagi H, Malmqvist B, Resch S, Hanning M: Waiting for orthopaedic surgery: factors associated with waiting times and patients' opinion. Int J Qual Health Care 2005, 17(2):133-140.

30. French DD, Bass E, Bradham DD, Campbell RR, Rubenstein LZ Rehospitalization after hip fracture: predictors and prognosis from a national veterans study. J Am Geriatr Soc 2008, 56(4):705-710.

31. lezzoni LI: Risk Adjustment for measuring healthcare outcomes. Health Administration Press; 32003.

32. Arcà M, Fusco D, Barone AP, Perucci CA: Risk adjustment and outcome research. Part I. J Cardiovasc Med (Hagerstown) 2006, 7(9):682-690.

33. Arcà M, Fusco D, Barone AP, e Perucci CA: Introduction to risk adjustment methods in comparative evaluation of outcomes. Epidemiol e Prev 2006, 30(4-5 suppl 1):1-48, in italian. 
34. Lovegrove J, Valencia O, Treasure T, Sherlaw-Johnson C, Gallivan S: Monitoring the results of cardiac surgery by variable life-adjusted display. Lancet 1997, 350(9085):1128-1130.

35. Foltran F, Baldi I, Bertolini G, Merletti F, Gregori D: Monitoring the performance of intensive care units using the variable life-adjusted display: a simulation study to explore its applicability and efficiency. $J$ Eval Clin Pract 2009, 15(3):506-513.

36. SAS Institute, Inc. SAS/STAT software, version 8. Cary, NC: SAS Institute, Inc; 1999.

37. Bradley EH, Holmboe ES, Mattera JA, Roumanis SA, Radford MJ, Krumholz HM: Data feedback efforts in quality improvement: lessons learned from US hospitals. Qual Saf Health Care 2004, 13:26-31.

38. Marshall MN, Shekelle PG, Davies HTO, Smith PC: Public reporting on quality in the United States and the United Kingdom. Health Aff (Millwood) 2003, 22(3):134-148.

39. Marshall MN, Shekelle PG, Leatherman S, Brook RH: The Public Release of Performance Data. What Do We Expect to Gain? A Review of the Evidence. JAMA 2000, 283(14):1866-1874.

40. Ugolini C, Nobilio L: Risk adjustment for coronary artery bypass graft surgery: an administrative approach versus EuroSCORE. Int J Qual Health Care 2004, 16:157-164.

41. Seccareccia F, Perucci CA, D'Errigo P, Arcà M, Fusco D, Rosato S, Greco D, Research Group of the Italian CABG Outcome Study: The Italian CABG Outcome Study: short-term outcomes in patients with coronary artery bypass graft surgery. Eur J Cardiothorac Surg 2006, 29:56-62.

42. Williams SC, Schmaltz SP, Morton DJ, Koss RG, Loeb JM: Quality of Care in U.S. Hospitals as Reflected by Standardized Measures, 2002-2004. N Engl $J$ Med 2005, 353:255-264.

43. Pitches DW, Mohammed MA, Lilford RJ: What is the empirical evidence that hospitals with higher-risk adjusted mortality rates provide poorer quality care? A systematic review of the literature. BMC Health Serv Res 2007, 20:91.

44. Lilford R, Pronovost P: Using hospital mortality rates to judge hospital performance: a bad idea that just won't go away. BMJ 2010, 340:c2016.

45. Winkel P, Zhang NF: Risk-Adjusted Control Charts. Statistical Development of Quality in Medicine John Wiley \& Sons, Ltd; 2007, 149-163.

46. Coory M, Duckett S, Sketcher-Baker K: Using control charts to monitor quality of hospital care with administrative data. Int J Qual Health Care 2008, 20(1):31-39.

47. Krumholz HM, Brindis RG, Brush JE, Cohen DJ, Epstein AJ, Furie K, Howard G, Peterson ED, Rathore SS, Smith SC Jr, Spertus JA, Wang Yand Normand S-LT: Standards for Statistical Models Used for Public Reporting of Health Outcomes. An American Heart Association Scientific Statement From the Quality of Care and Outcomes Research Interdisciplinary Writing Group. Circulation 2006, 113:456-462.

48. Shekelle PG, Lim YW, Mattke S, Damberg C: Does public release of performance results improve quality of care? A systematic review. London. The Health Foundation 2008 [http://www.health.org.uk/ publications/does-public-release-of-performance-results-improve-quality-ofcare/\#].

49. Lazio Region. Resolution no. 613. Official Bulletin of the Lazio Region 2009, 34(163 supp.)

50. Mannion R, Goddard M: Public disclosure of comparative clinical performance data: lessons from the Scottish experience. J Eval Clin Pract 2003, 9:277-286.

51. Sofaer S, Crofton C, Goldstein E, Hoy E, Crabb J: What do consumers want to know about the quality of care in hospitals? Health Serv Res 2005, 40:2018-2036.

52. The Kaiser Family Foundation, Agency for Healthcare Research and Quality, Harvard School of Public Health: National Survey on Consumers' Experiences with Patient Safety and Quality Information. Summary and Chart Pack 2004 [http://www.kff.org/kaiserpolls/pomr111704pkg.cfm].

53. Mohammed MA, Deeks JJ, Girling A, Rudge G, Carmalt M, Stevens AJ, Lilford RJ: Evidence of methodological bias in hospital standardised mortality ratios: retrospective database study of English hospitals. BMJ 2009, 338:b780.

54. Aylin P, Bottle A, Majeed A: Use of administrative data or clinical databases as predictors of risk of death in hospital: comparison of models. BMJ 2007, 334(7602):1044.

55. Johnston TC, Coory MD, Scott I, Duckett S: Should we add clinical variables to administrative data? The case of risk-adjusted case fatality rates after admission for acute myocardial infarction. Med Care 2007, 45:1180-1185.

56. Pine M, Jordan HS, Fry DE, Hoaglin DC, Jones B, Meimban R, Warner D, Gonzales J: Enhancement of claims data to improve risk adjustment of hospital mortality. JAMA 2007, 297(1):71-76.

57. Glance LG, Osler TM, Mukamel DB, Dick AW: Impact of the present-onadmission indicator on hospital quality measurement: experience with the Agency for Healthcare Research and Quality (AHRQ) Inpatient Quality Indicators. Med Care 2008, 46(2):112-119.

58. Quan H, Parsons GA, Ghali WA: Validity of information on comorbidity derived from ICD-9-CM administrative data. Med Care 2002, 40(8):675-685

59. Elixhauser A, Steiner C, Harris DR, Coffey RM: Comorbidity measures for use with administrative data. Med Care 1998, 36(1):8-27.

60. Modifica del contenuto informativo della rilevazione dei dati sulle dimissioni ospedaliere per pazienti acuti. Lazio Region 2007, Resolution D4118 http://www.asplazio.it/.

61. Lee DS, Donovan L, Austin PC, Gong Y, Liu PP, Rouleau JL, Tu JV: Comparison of coding of heart failure and comorbidities in administrative and clinical data for use in outcome research. Med Care 2005, 43(2):182-188.

62. Rangachari P: Coding for Quality Measurement: the Relationship between Hospital Structural Characteristics and Coding Accuracy from the Perspective of Quality Measurement. Perspect Health Inf Manag 2007, $4: 3$.

63. Serumaga B, Ross-Degnan D, Avery AJ, et al: Effect of pay for performance on the management and outcomes of hypertension in the United Kingdom: interrupted time series study. BMJ 2011, 342:d108.

64. Werner RM, Konetzka RT, Stuart EA, et al: Impact of public reporting on quality of postacute care. Health Serv Res 2009, 44:1169-87.

65. Fortuna D, Vizioli M, Contini A, et al: Assessing clinical performance in cardiac surgery. Does a specialised clinical database make a difference? Interact Cardiovasc Thorac Surg 2006, 5:123-127.

66. Shahian DM, Wolf RE, lezzoni LI, Kirle L, Normand SLT: Variability in the Measurement of Hospital-wide Mortality Rates. N Engl J Med 2010, 363:2530-9.

\section{Pre-publication history}

The pre-publication history for this paper can be accessed here: http://www.biomedcentral.com/1472-6963/12/25/prepub

doi:10.1186/1472-6963-12-25

Cite this article as: Fusco et al.: P.Re.Val.E.: outcome research program for the evaluation of health care quality in Lazio, Italy. BMC Health Services Research 2012 12:25.

\section{Submit your next manuscript to BioMed Central and take full advantage of:}

- Convenient online submission

- Thorough peer review

- No space constraints or color figure charges

- Immediate publication on acceptance

- Inclusion in PubMed, CAS, Scopus and Google Scholar

- Research which is freely available for redistribution

Submit your manuscript at www.biomedcentral.com/submit
C Biomed Central 